\title{
Mediação de lendas urbanas na Biblioteca Pública Municipal Lupércio Luppi
}

\author{
Mediation of urban legends in the Municipal Public Library Lupércio \\ Luppi
}

\author{
Ana Paula Pereira \\ Graduação em Biblioteconomia pela Universidade Estadual de Londrina - UEL. \\ E-mail: appuel@yahoo.com.br \\ Marinalva Luiza de Almeida \\ Graduação em Biblioteconomia pela Universidade Estadual de Londrina. \\ E-mail: nalvinha@uel.br
}

\begin{abstract}
João Arlindo dos Santos Neto
Doutorando pelo Programa de Pós-Graduação em Ciência da Informação da Universidade Estadual Paulista Júlio de Mesquita Filho (Unesp), Faculdade de Filosofia e Ciências, Campus de Marília. Professor Colaborador/Assistente do Departamento de Ciência da Informação da Universidade

Estadual de Londrina - UEL.

E-mail: santosneto@uel.br
\end{abstract}

\section{Resumo}

Aborda a mediação da leitura e a contação de história como atividades essenciais para as crianças. Destaca que a leitura da palavra escrita está associada a outras leituras possíveis de serem realizadas. Salienta que os familiares, os professores e os bibliotecários são os principais mediadores de leitura na vida das crianças. Defende que as lendas urbanas são narrativas culturais e coletivas, produto do conhecimento popular, que podem ser utilizadas na mediação da leitura. Tem como objetivos investigar a mediação de lendas urbanas na Biblioteca Pública Municipal Lupércio Luppi e demonstrar o significado da apropriação das lendas urbanas pelas crianças nas atividades de contação de história. Como método de pesquisa foi utilizado a observação e análise de uma contação de lendas urbanas da cidade de Londrina. Conclui que a mediação da leitura contribui para o desenvolvimento da criança, assim como para a formação do gosto pela leitura, sendo necessário o envolvimento dos familiares, dos professores e dos bibliotecários.

Palavras-chave: Mediador da leitura. Contação de história. Lendas urbanas.

\begin{abstract}
Addresses the mediation of reading and storytelling as essential activities for children. It points out that the written word reading is associated with other possible readings to be performed. It stresses that family, teachers and librarians are the main reading mediators in children's lives. It argues that urban legends are cultural and collective narratives of popular knowledge product, which can be used in reading mediation. It aims to investigate the mediation of urban legends in the Public Library Municipal Lupércio Luppi and demonstrate the significance of the appropriation of urban legends for children in the storytelling activities. As a research method used was the observation and analysis of a story-urban legends of the city of Londrina. It concludes that reading mediation contributes to the development of the child, as well as the formation of the taste for reading, requiring the involvement of family members, teachers and librarians.
\end{abstract}

Keywords: Reading mediator. Storytelling. Urban legends. 


\section{Introdução}

A mediação da leitura é uma ação essencial para formação cognitiva e intelectual da criança. E para propiciar o desenvolvimento do ato de ler de forma mais atrativa e prazerosa, é necessário aproximar o leitor do texto, isto é, desenvolver atividades como a contação de história a fim de estabelecer uma relação direta e criativa entre mediador, ou contador de história, e a criança.

Nesse sentido, a mediação de lendas urbanas cumpre seu papel ao resgatar a tradição, a cultura local e também fomentar a leitura, seja por meio da imaginação e do mistério advindos de narrativas da cultura popular, seja na adaptação para o contexto urbano. Isso porque tais narrativas possuem elevado poder de encantamento, principalmente ao despertar emoções e sentimentos como o medo do desconhecido.

Esta proposta se justifica ao demonstrar o significado da mediação da leitura e a importância da atividade de contação de lendas urbanas para as crianças. O objetivo deste artigo foi investigar de que maneira se realiza a mediação da leitura e a contação de lendas urbanas na Biblioteca Pública Municipal Lupércio Luppi, localizada na cidade de Londrina/PR.

Dessa forma, buscamos analisar a contação de lendas urbanas do Projeto Lendas Urbanas de Londrina: histórias para ouvir e contar realizado na referida Biblioteca. Como técnica de coleta de dados utilizamos a observação do ato de narrar as lendas bem como as reações dos ouvintes. 


\section{O significado da leitura}

A leitura desempenha uma função essencial na vida do indivíduo. Paulo Freire (1991) afirma que ler é um ato envolvente, que requer e exige a capacidade de ir além do simples decifrar letras e formar palavras. Isso significa que não basta apenas e tão somente "conhecer o ABC”, mas com ele ir além ao associá-lo à realidade. Segundo o autor, esta relação é contínua e se constitui com a leitura do mundo e com a leitura da palavra.

Se aprender é relembrar, ler é reconhecer (conhecer novamente) a palavra por meio do mundo e o mundo por meio da palavra. Daí tem origem a leitura crítica, aquela que nos permite perceber, identificar, refletir, pensar sobre as conexões do texto com seu contexto num encontro existencial, de memória, de vivência entre o eu e o mundo.

Côrte e Bandeira (2011, p.1) salientam que a leitura da palavra não é única, assim:

A leitura é mais que isso. É uma experiência individual por excelência. Abrange muitos significados. Ao ouvir uma música, ao admirar uma pintura, quando sentimos o sabor de uma deliciosa comida, o cheiro da terra molhada, o cheiro de um bebê, a força e a massagem em nossos pés quando andamos na areia de belas praias, o vento frio a bater no rosto, enfim tudo o que sentimos, vemos e ouvimos, está relacionado ao processo da leitura. A leitura possibilita prazeres, saberes, reflexões e ações.

Conhecemos e vivemos outras leituras desde o primeiro contato com o universo das coisas, com a realidade em que estamos inseridos. De fato, nossas experiências pessoais são fonte de leitura: cada cor, sabor, gesto, som, imagem, a maneira como os observamos são leituras inerentes a nós mesmos. Quanto mais nos aproximamos da leitura das coisas, mais descobrimos o mundo que se vai constituindo. Nesse sentido, Resende (1993, p.15) afirma que

Ler supõe um olhar de reconhecimento, mas não só sobre letras e sons. É prestar atenção para entender, captar, desvelar; é ouvir e silenciar-se, quando no interior ficam guardados os sentidos recolhidos; é imaginar, indo além do que os olhos alcançam e do que os limites reais oferecem; é entrar nas coisas, colocar-se nelas e sentir-se enriquecido nessa relação; é envolver-se sem restrições e compreender o que se buscou.

Na medida em que lemos, escrevemos e reescrevemos o mundo, alcançamos não somente a autonomia do pensamento, mas a dignidade, a transformação e a transcendência do indivíduo capaz de pensar por si mesmo, de imprimir mudanças, e de agir de maneira consciente, crítica e justa. Além disso, 
Ana Paula Pereira, Marinalva Luiza de Almeida e João Arlindo dos Santos Neto

\begin{abstract}
A leitura, especialmente, permite adentrar no mundo do encantamento literário, não sendo voltada apenas para as questões práticas ou utilitárias. É, também, um ato de simbolização do mundo, cujas dimensões se prolongam a partir das experiências históricas de cada um e percorrem a intersubjetividade dos lugares e do tempo, criando histórias, mitos, heróis, lendas, "causos", significados e sentidos que auxiliam a interpretar o mundo e a presença humana nele [...] (CAVALCANTE, 2015, p.108).
\end{abstract}

Concordamos com o referido pensamento, pois concebemos a leitura de modo lato, isto é, como algo que ultrapassa o caráter funcional e que permite diversas possibilidades. Discordamos, por exemplo, dos mecanismos de avaliação existentes em algumas escolas para verificar a compreensão do aluno após a leitura de um texto, escrito ou não, que muitas vezes é norteado a partir de uma visão simplista e reducionista.

Nesse sentido, os mediadores da leitura, dentre os quais destacamos o bibliotecário e o professor devem propiciar uma experiência diferente e consciente de leitura, ou seja, um mergulho no texto, não superficial, mas profundo, questionador, capaz de encantar e de provocar o leitor. Portanto, a seção a seguir destina-se a discussão a respeito destes profissionais, que medeiam ao mesmo tempo, informação e leitura.

\title{
3. O mediador da leitura
}

O mediador de leitura pode ser definido como o indivíduo que pode estabelecer e criar a relação de proximidade entre o leitor e o texto independentemente do seu suporte. $\mathrm{Na}$ concepção de Bortolin (2007) o mediador de leitura é:

Aquele indivíduo que aproxima o leitor do texto. Em outras palavras, o mediador é o facilitador desta relação. E como intermediário de leitura, o mediador encontra-se em uma situação privilegiada, pois tem nas mãos a possibilidade de levar o leitor a infinitas descobertas.

Sendo assim, o mediador tem a habilidade necessária para facilitar o processo de leitura, isto é, a aproximação ou contato do leitor com o texto. Deste modo, a mediação da leitura pode ser entendida também como a ação de formação de leitores.

Da mesma maneira, Russo (2011) entende a mediação da leitura, como "[...] ato de ler para crianças, jovens ou adultos, de uma maneira livre e prazerosa [...]”. A autora, concordando com especialistas desta área, ressalta que esta atividade tem como principal objetivo introduzir o livro no cotidiano do leitor, buscando atraí-lo pelo conteúdo, mas também pelo formato a fim de incentivar o ato de ler, despertar e aumentar o gosto pela leitura. Entretanto, 
Mediação de lendas urbanas na Biblioteca Pública Municipal Lupércio Luppi

Não basta colocar um livro, a qualquer custo e a qualquer tempo, na mão de uma criança sem que haja uma ligação entre o que ela lê e sua história, seu referencial de vida, seu próprio ambiente. É preciso que se crie uma identificação entre ela e a leitura. [...] é preciso que haja uma ligação para haver interesse, motivação, a vontade de seguir adiante, para saber aonde vai dar essa estória. (CÔRTE; BANDEIRA, 2011, p. 2).

Importante destacar que há além do livro, outros recursos que o leitor pode se apropriar como forma de acesso livre e infinito à leitura, não se restringindo a um suporte ou gênero apenas. Reforçamos mais uma vez que, neste artigo, referimo-nos a leitura de modo lato, portanto, aquela que pode ser feita em qualquer suporte.

Não somente as crianças podem beneficiar-se de uma mediação de leitura. Qualquer indivíduo, independentemente da idade pode participar dessa atividade. No entender de Russo (2011) a mediação da leitura “[...] não exige do mediador grandes habilidades artísticas". Concordamos com a autora uma vez que o mediador não precisa ser um ator, porém deve demonstrar liberdade e prazer durante a atividade, ser autêntico na ação e na atuação de compartilhamento de leituras. Além disso, acrescentamos que o mediador precisa primeiramente ser leitor e ter prazer pela leitura.

A esse respeito, Rasteli (2013, p.16) evidencia que a contribuição do mediador de leitura está na apropriação, seja de significados ou de sentidos os quais o leitor pode atribuir, assim:

O mediador destaca-se por sua intenção de contribuir na apropriação de significados, no processo de interação do leitor com o texto, nas experiências de aprendizagens, [...] despertando suas competências. A mediação da leitura coloca em evidência o papel de sujeito construtor do conhecimento. Conhecimento que se incorpore ao mundo intelectual e vivencial do leitor e que o ajude a compreender sua realidade humana $\mathrm{e}$ social, agindo e interferindo nela.

O autor entende que a mediação possibilita a aprendizagem, potencializa as habilidades e desenvolve as competências do leitor, além de ajudá-lo a compreender a realidade e agir sobre ela. Cavalcante (2015, p.109) completa dizendo que

A mediação da leitura [...] amplia a noção de texto, indo além da palavra escrita, e se abre em um processo de comunicação, ancorado na interação social, estabelecendo as condições necessárias para a produção e apropriação de sentidos a partir das experiências vividas individualmente e de ambos: mediador e leitor.

Portanto, o mediador de leitura e o contador de história desempenham papéis significativos, pois ao compartilhar experiências e emoções, podem conduzir o leitor ao caminho de novas leituras, aprendizados e ações. Os familiares, os professores e os 
bibliotecários são os principais mediadores de leitura na vida da criança, e:

[...] deveriam ser os primeiros mediadores de leitura, pois são os primeiros elos da criança com o mundo; entretanto os pais e demais membros da família, em geral, não têm a dimensão da influência que podem exercer sobre as crianças, no sentido de motivá-las à leitura. (BORTOLIN, 2007).

A autora defende que os familiares deveriam estabelecer o primeiro contato da criança com a leitura, isto é, ser os primeiros mediadores inserindo-a ainda que inicialmente, no mundo da leitura. No entanto, lembra que muitas famílias não possuem condições econômicas para exercer essa atividade. Neste caso, cabe aos professores e bibliotecários a responsabilidade de aproximar a criança da leitura, de maneira mais prazerosa possível.

Russo (2011) acrescenta que a mediação da leitura pode ocorrer em vários locais, mas a biblioteca escolar e a biblioteca pública são ideais para sua realização, porque geralmente, seus usuários têm o poder aquisitivo reduzido o que os impossibilita de adquirir livros frequentemente.

Some-se a isso o fato de que a biblioteca pública é um dos poucos (ou único) ambientes de leitura que os leitores têm acesso. Daí a necessidade de se realizar atividades de mediação e de contação de história, temática discutida a seguir.

\section{Contação de história}

Entendemos que esta prática é significativa para a vida das crianças, pois aproximará os sujeitos, crianças ou adultos, da leitura. Cavalcante $(2015$, p.117) evidencia que “[...] a contação de história, ancorada no conceito de mediação, tem assumido papel de destaque no Brasil, nas últimas décadas permitindo que o texto literário ganhe voz e conquiste o leitor em diferentes ambiências $[\ldots] ”$.

No entender de Abramovich (2001, p.16) “[...] é importante para formação de qualquer criança ouvir muitas, muitas histórias... Escutá-las é o início da aprendizagem para ser um leitor, e ser leitor é ter um caminho absolutamente infinito de descoberta e de compreensão de mundo..." Assim, quem houve histórias, desenvolve o ato de ler, de descobrir e de compreender o mundo.

Como afirma a autora, ouvir histórias pode provocar diferentes emoções: 
É ouvindo histórias que se pode sentir (também) emoções importantes, como a tristeza, a raiva, a irritação, o bem-estar, o medo, a alegria, o pavor, a insegurança, a tranqüilidade, e tantas outras mais, e viver profundamente tudo o que as narrativas provocam em quem as ouve - com toda a amplitude, significância e verdade que cada uma delas fez (ou não) brotar.... Pois é ouvir, sentir e enxergar com os olhos do imaginário! (ABRAMOVICH, 2001, p.17).

Portanto, aquele que ouve histórias experimenta sensações e sentimentos diversos que variam conforme a intensidade da narrativa, emoções às vezes contraditórias ou não, ainda assim é saudável vivenciá-las. Schneid (2008, p. 3) chama a atenção para os relatos sobre a importância da contação no desenvolvimento da criança, pois possui caráter recreativo, educativo, instrutivo, afetivo. Ao ampliar horizontes, estimula a criatividade, cria hábitos, desperta emoções, valoriza sentimentos, sociabiliza, entre outros.

Em relação a tal aspecto, Barcellos e Neves (1995 apud FLECK, 2007, p.216) salientam que a criança que ouve histórias com frequência "[...] educa sua atenção, desenvolve a linguagem oral e escrita, amplia seu vocabulário e principalmente, aprende a procurar, nos livros, novas histórias para o seu entretenimento". Este último aspecto é essencial, pois estimular o aprendizado em busca de narrativas nos livros, fomenta e incentiva a leitura.

Portanto, em se tratando de crianças, a participação em contação de história favorece aspectos afetivo, social, cognitivo, bem como a aprendizagem. Por isso, o ato de contar história também se destina a todos os públicos, idades ou classes sociais.

\footnotetext{
A criança e o adulto, o rico e o pobre, o sábio e o ignorante, todos, enfim, ouvem com prazer as histórias - uma vez que essas histórias sejam interessantes, tenham vida e possam cativar a atenção. A história narrada, lida, filmada ou dramatizada, circula em todos os meridianos, vive em todos os climas. Não existe povo algum que não se orgulhe de suas histórias, de suas lendas e de seus contos característicos. (TAHAM, 1957, p. 15).
}

Concordamos com a autora ao dizer que as histórias contadas fascinam à todos, sem excluir indivíduos e sociedades desde que tenham o potencial de "seduzir" e maravilhar os ouvintes. Fleck (2007, p. 220) acrescenta que “A valorização da cultura popular e dos contos tradicionais por intermédio da narração de histórias é muitas vezes uma maneira de resguardar a origem e a própria história de cada localidade ou região [...]”. Dentre elas, destacamos as lendas urbanas, conforme apresentamos na seção seguinte. 


\section{Lendas urbanas}

No entender de Pellegrini Filho (2000, p. 58) a lenda é uma “[...] narrativa popular de caráter maravilhoso, associada a determinado lugar e/ou determinado tempo no passado". O autor salienta que a lenda, como manifestação visa compreender o universo e afirmar valores socioculturais. E completa dizendo que a lenda é uma narrativa, oral ou escrita caracterizada pelo elemento maravilhoso ou sobrenatural presente nas manifestações da fantasia.

Neste trabalho abordamos as lendas urbanas, isto é, narrativas que podem despertar a curiosidade pelo sobrenatural, o fascínio pelo desconhecido, pelo inexplicável, pelo “fantástico". Sob o ponto de vista de Sylvestre (2012), as lendas urbanas são:

Histórias que nascem na literatura oral e vão sendo transmitidas de geração para geração, com variações, dependendo da região em que são contadas. São narrativas essencialmente de cunho insólito, já que traduzem um universo ligado ao medo, ao terror, ao sobrenatural, ao desconhecido.

Portanto, as lendas urbanas têm origem na oralidade, se vinculam à tradição e estão no espaço de intersecção do real e do sobrenatural. Geralmente relacionadas à realidade, elas apresentam fatos, datas e locais reais para atribuir um caráter de veracidade a narrativa. Estes elementos podem sofrer alterações ao longo do tempo, por se tratar de uma narrativa construída cultural e coletivamente. Assim “[...] como um texto de cultura, a lenda urbana é condensadora da memória cultural já formada na consciência de quem a ouve ou a narra [...]" (MOREIRA, 2010, p. 17).

Sob essa perspectiva, Dion (2008, p. 1) enfatiza que as lendas urbanas são “[...] narrativas coletivas carregadas de efeitos de verdade [...] que fazem parte do conhecimento popular e da cultura informal". Dessa maneira, as lendas urbanas contêm elementos verdadeiros e reais que se constituem em conhecimento da coletividade. Ainda segundo Dion $(2008$, p. 3):

[...] a lenda contemporânea ou urbana é uma narrativa oral, exemplar, coletiva, anônima, que possui uma mensagem implícita e uma moral escondida à qual nos ligamos. Ancorada na cidade e na modernidade, baseada na crença, requerendo igualmente a cumplicidade de um ouvinte, a lenda urbana tem por objetivo explicar o inexplicável e o incompreensível, de acordo com o sistema de valores, a época e a visão de mundo da comunidade na qual ela se inscreve.

Nesse sentido, a autora identifica elementos como a oralidade e as "lições" ou os "ensinamentos" camuflados, os quais se atrelam aos receptores com intuito de compreender o mistério segundo princípios e perspectivas do próprio grupo ao qual a lenda urbana pertence. Ainda que "[...] a lenda urbana [...] contenha elementos misteriosos, aposta no realismo, 
apoiando-se nas crenças e nos medos atuais". (DION, 2008, p. 12). Dessa forma, o mistério torna-se um elemento necessário, contudo, os medos de hoje, provocam tanta inquietação quanto o desconhecido.

Steffen ([200?]) também destaca aspectos significativos das lendas urbanas, que aproximam o leitor:

Tais estruturas narrativas, fabulosas, mas nem sempre falaciosas, apresentando elementos de mistério, horror e medo, se passam em ambientes triviais e tratam de personagens comuns, de modo que o leitor pode facilmente se identificar com eles.

Concordamos com a autora quando afirma que determinados papéis ou lugares do cotidiano do leitor favorecem a identificação com a narrativa. Para isso é necessário propiciar o "encontro" do leitor com as lendas urbanas, a exemplo do projeto que apresentamos a seguir.

\subsection{Projeto lendas urbanas de Londrina: histórias para ouvir e contar}

Em 2012, algumas bibliotecárias do Sistema de Bibliotecas Públicas Municipais de Londrina participaram do Projeto de Caso com a Palavra que se constituía na formação de mediadores. Elas foram convidadas, pois haviam trabalhado em bibliotecas escolares realizando contação de história.

No referido projeto era necessário elaborar um subprojeto; daí resultou o Projeto Lendas Urbanas de Londrina: histórias para ouvir e contar que foi inspirado em um quadro do Sistema Brasileiro de Televisão (SBT), porque na época, as crianças estavam envolvidas com as lendas contadas no programa. Assim, as bibliotecárias verificaram a importância de resgatar as lendas urbanas no contexto de Londrina.

O projeto foi selecionado e apresentado em outras cidades. Em comemoração aos 80 anos de Londrina, a contação de lendas foi realizada no Sistema de Bibliotecas Públicas Municipais da cidade: Ramal Vila Nova, Centro Cultural Lupércio Luppi e Biblioteca Infantil Municipal de Londrina.

As bibliotecárias enfatizam que "As histórias [contadas] provocam um alívio das pressões e para a criança é fundamental o ir e vir do imaginário, a fantasia." Momento significativo da mediação ocorre quando as crianças compartilham e participam da atividade contando lendas. 
A partir deste Projeto, os mediadores produziram um livro artesanal ${ }^{1}$ que reúne as lendas urbanas de Londrina e algumas lendas escritas por crianças participantes da mediação. Isso porque após contar as lendas elas eram estimuladas a escrevê-las; sendo que algumas foram selecionadas e incluídas no livro.

\section{Procedimentos metodológicos}

O artigo é de caráter descritivo e natureza qualitativa, visto que procuramos descrever a mediação, destacando sua importância e relações com a leitura. A abordagem qualitativa permite a busca, a análise e interpretação mais aprofundada dos dados, por isso, possibilita a investigação da mediação de forma mais precisa e detalhada. A opção pelo estudo qualitativo justifica-se também pela amostra reduzida da pesquisa realizada.

Para coleta dos dados utilizamos a técnica de observação de uma narrativa de lendas urbanas, a partir de um roteiro preestabelecido. Gil (2008, p. 100) ao compará-la com outras técnicas afirma que na observação "[...] os fatos são percebidos diretamente [...] Desse modo, a subjetividade, que permeia todo processo de investigação social, tende a ser reduzida".

O universo de pesquisa é o Sistema de Bibliotecas Públicas Municipais de Londrina e a Biblioteca Pública Municipal Lupércio Luppi constitui o campo alvo de estudo. Inaugurada em 2004, a biblioteca pertence ao Centro Cultural Lupércio Luppi que está localizado na Avenida Saul Elkind na zona norte da cidade de Londrina, Paraná (LONDRINA, 2016).

Participaram desta pesquisa 25 crianças com idade entre 9 e 10 anos e 2 bibliotecárias. Como técnica para análise dos dados, observamos as lendas contadas, as reações das crianças, as ações das narradoras e as atividades desenvolvidas. A seguir, apresentamos os resultados da análise de dados.

\footnotetext{
${ }^{1}$ Ventura et al. (2012).
} 


\section{Resultados e discussão}

Foi possível notar que as bibliotecárias organizaram os assentos em forma circular para receber as crianças que estudam em uma escola pública localizada nas proximidades da biblioteca. Elas procuraram deixá-las bem à vontade e iniciaram a mediação questionando-as quanto ao conhecimento sobre lendas urbanas, com as seguintes questões: "Vocês sabem o que são lendas urbanas?" "Cite uma lenda urbana que você conhece”. Algumas crianças citaram lendas do folclore brasileiro, como a lenda do saci. A partir desse exemplo, as mediadoras mencionaram que a contação foi resultado de um curso que participaram para contar histórias e que na época escolheram as lendas devido ao programa do SBT sobre lendas urbanas.

Após a contextualização, explicaram porque a lenda do saci não é urbana e definiram lendas urbanas como lendas que acontecem especificamente em uma cidade, contada a partir de narrativas orais e que despertam sentimentos distintos ao público mediado, compartilhando a memória e os costumes de uma região (STEFFEN, [200?]; DION, 2008; MOREIRA, 2010). Além disso, foi exposto de forma clara que nunca há certeza do acontecimento narrado, ou seja, as histórias provavelmente aconteceram, mas a dúvida é o elemento que permanece em todas as lendas.

As bibliotecárias também comentaram que o projeto se refere especificamente as lendas urbanas de Londrina, lembrando que cada cidade tem suas lendas, enfatizando que não se sabe onde está a verdade ou a mentira.

No momento da contação, foram utilizados objetos, a fim de inserir as crianças no cenário da lenda contada, dentre os quais, pequenas rosas artificiais (vermelhas e brancas) e uma cartola. Este último, segundo as contadoras tem a função semelhante à uma máscara, uma ponte que leva da realidade para fantasia. Portanto, é um recurso utilizado para a criança entender que ela está deixando a realidade e entrando no "universo do sobrenatural".

As lendas urbanas contadas foram "O grande golpe de 40", "Rosas vermelhas" e "A bela adormecida de Londrina”. Durante a contação, observamos a ênfase dada em locais reais: Londrina, Hospital Santa Casa, Rua Rio de Janeiro, entre outros elementos que aproximam o ouvinte à narrativa, pois ao reconhecer esses espaços ele se identifica. Notamos que a cada ambiente apresentado, eram feitos outros questionamentos: "Vocês conhecem essa rua ou o hospital?", e as respostas foram: "Sim, nasci lá” ou "meu irmão foi internado lá...” 
Entre uma lenda e outra, as bibliotecárias questionaram a veracidade da história, instigando os ouvintes a refletir: "É verdade essa história?" e foram esclarecendo alguns aspectos de acordo com a resposta afirmativa ou negativa das crianças como no caso da lenda da "Bela adormecida de Londrina", explicando que de fato existe uma doença em que a pessoa dorme por muito tempo.

Percebemos que a lenda "Rosas vermelhas" provocou mais envolvimento por parte das crianças. Ao serem questionadas sobre a cor das rosas, isto é: "Que rosas vocês acham que ela trouxe?" a resposta foi imediata: "rosas vermelhas!".

Após a contação, as crianças foram convidadas a contar lendas que conheciam sendo motivadas a utilizar a cartola e foi possível notar o interesse em apropriar-se do objeto. Ao final, as narradoras incentivaram a leitura apresentando livros sobre lendas urbanas, dentre os quais, o livro artesanal produzido por elas. Além disso, as crianças também foram motivadas a desenhar as lendas que ouviram durante a contação e a escrever as lendas que contaram para a produção de um novo livro. Nesse momento, aquelas que não contaram também demonstraram desejo de escrever.

Constatamos que as crianças participaram da atividade e permaneceram atentas durante a mediação, sendo que três contaram lendas. A princípio demonstrando timidez por apresentarse diante dos colegas, mas aos poucos isso foi superado. Percebemos que se houvesse mais tempo disponível, mais crianças teriam participado contando lendas.

Entre as atitudes das crianças, foi possível notar reações como medo, expressões faciais de espanto, a crença na veracidade dos fatos, e sua relação com o real, o que ficou evidente nos olhares atentos e nas manifestações espontâneas como, por exemplo: "É verdade, minha mãe contou", "Isso é prova da existência do sobrenatural" e ainda "Nunca quero receber rosa vermelha". 


\section{Considerações finais}

A mediação aqui apresentada é uma iniciativa de incentivo à leitura que aproxima as crianças e as lendas urbanas por meio da oralidade, da produção textual e da ilustração. Analisando a atividade, percebemos que a proposta do Projeto Lendas Urbanas de Londrina: histórias para ouvir e contar se constituiu em uma estratégia diferenciada de mediação, tendo em vista que além de resgatar a cultura local, possibilitou o compartilhamento de narrativas e a inversão de papéis: as crianças ouvintes tornaram-se contadoras. Além disso, as crianças conhecem e discutem sobre as lendas que permeiam a cidade em que nasceram ou residem.

Verificamos o empenho dos bibliotecários em preparar o ambiente "ideal" para seus ouvintes, ao utilizar objetos que favorecem o encantamento como a cartola e as flores, a fim de mesclar realidade e fantasia. Para isso, foi fundamental o apoio da escola e da professora propiciando a ida e a participação das crianças. Ressaltamos que em relação a ambientação do espaço, a criatividade é mais importante do que os recursos financeiros disponibilizados pelo equipamento informacional/cultural.

Constatamos o entusiasmo dos mediadores ao deslocar-se até a biblioteca pública, na preocupação em auxiliar a professora, no percurso da escola até a biblioteca e no retorno para sala de aula e também o envolvimento das crianças em toda proposta: ouvir, contar, ilustrar e o entusiasmo em produzir textos, ao descobrir que suas lendas poderiam compor um novo livro. Acreditamos que essa proposta, integra ainda mais os participantes, visto que eles fazem parte e são coprodutores de um objeto cultural, como o livro.

Essa experiência evidencia a possibilidade de criação e desenvolvimento de atividades de mediação de leitura e contação de história que visam à formação de leitores motivados, interessados e inquietos. Para isso, é necessário que a biblioteca pública e a escola atuem no sentido de provocar nas crianças o desejo pela leitura múltipla, incluindo as lendas urbanas. Ressaltamos que a escolha pelas lendas urbanas pode ser mais atrativa que outras temáticas, pois remetem ao cotidiano das crianças, isto é, a cidade em que mora e/ou nasceu, nome da escola, da rua, da praça etc.

Nesse sentido, cabe também aos familiares valorizar a mediação da leitura, oportunizando à criança tanto a apropriação cultural e informacional quanto dos espaços em que ocorrem, como a biblioteca pública, sem relacionar este ambiente as atribuições escolares. A escola deve programar-se para a atividade, pois esta mediação interferirá no contexto das 
crianças e como vimos, quando isso ocorre, a ação realiza-se de maneira plena e participativa. Consequentemente, os bibliotecários, na medida em que procuram desenvolver atividades conforme o gosto de seus leitores, obtêm êxito em suas propostas.

Os resultados deste trabalho evidenciaram que a mediação da leitura e a contação de história para as crianças é significativa, pois ao frequentar a biblioteca pública, elas se aproximam de narrativas culturais, em especial das lendas urbanas de Londrina, e do mediador. Neste caso, os bibliotecários estavam atentos às preferências das crianças presente em outros meios como a televisão e com maestria adaptaram as lendas urbanas para o contexto da biblioteca. Assim sendo, este projeto pôde resgatar e (re) construir a memória cultural das crianças e da cidade de Londrina.

\section{Referências}

ABRAMOVICH, F. Literatura infantil: gostosuras e bobices. 5.ed. São Paulo: Scipione, 2001.

BORTOLIN, S. O mediador de leitura. 2007. Disponível em:

<http://www.ofaj.com.br/colunas_conteudo.php?cod=302>. Acesso em: 03 out. 2016.

CAVALCANTE, L. E. Mediação e narrativa na voz dos contadores de histórias. In: BORTOLIN, S.; SANTOS NETO, J. A.; SILVA, R. J. (Org.). Mediação oral da informação e da leitura. Londrina: ABECIN, 2015. p. 107-125.

CÔRTE, A. R.; BANDEIRA, S. P. Biblioteca escolar. Brasília: Briquet de Lemos, 2011.

DION, S. A lenda urbana: um gênero narrativo de grande mobilidade cultural. Boitatá Revista do GT de Literatura Oral e Popular da ANPOLL, Londrina, n. 6, p. 1-13, ago./dez., 2008. Disponível em:

<http://www.uel.br/revistas/boitata/volume_6_2008/lenda\%20urbana\%20Sylvie\%20Dion\%2 0ok.pd>. Acesso em: 03 out. 2016.

FLECK, F. O. O contador de histórias: uma nova profissão? Encontros Bibli: revista eletrônica de biblioteconomia e ciência da informação, Florianópolis, v. 12, n. 23, p. 216227, 2007. Disponível em: <https://periodicos.ufsc.br/index.php/eb/article/view/15182924.2007v12n23p216/404>. Acesso em: 03 out. 2016.

FREIRE, P. A importância do ato de ler: em três artigos que se completam. São Paulo: Cortez; Autores Associados, 1991.

GIL, A. C. Métodos e técnicas de pesquisa social. 6. ed. São Paulo: Atlas, 2008.

LONDRINA. Prefeitura de Londrina. Centro Cultural Lupércio Luppi. 2016. Disponível em: 
<http://www.londrina.pr.gov.br/index.php?option=com_content $\&$ view=article $\& i d=227 \&$ Item $\mathrm{id}=302>$. Acesso em: 03 out. 2016.

MOREIRA, N. E. P. Lendas urbanas: atualização, persistência e "realidade" nessas narrativas multimídia. Dissertação (Mestrado em Comunicação e Semiótica) - Pontifícia Universidade Católica de São Paulo. São Paulo, 2010. Disponível em:

$<$ http://sapientia.pucsp.br/bitstream/handle/5325/1/Natalia\%20Eunice\%20Paiva\%20Moreira. pdf >. Acesso em: 03 out. 2016.

PELLEGRINI FILHO, A. Literatura folclórica. São Paulo: Manole, 2000.

RASTELI, A. Mediação da leitura em bibliotecas públicas. Dissertação (Mestrado em Ciência da Informação) - Universidade Estadual Paulista. Marília, 2013. Disponível em: $<$ http://www.marilia.unesp.br/Home/Posgraduacao/CienciadaInformacao/Dissertacoes/rasteli_a_me_mar.pdf >. Acesso em: 03 out. 2016.

RESENDE, V. M. Literatura infantil \& juvenil: vivências de leitura e expressão criadora. São Paulo: Saraiva, 1993.

RUSSO, M. O resgate dos bibliotecários. 2011. Disponível em:

<http://revistaeducacao.com.br/textos/o-resgate-dos-bibliotecarios>. Acesso em: 03 out. 2016. Não paginado.

SCHNEID, J. T. N. Hora do conto: uma experiência maravilhosa. In: CONGRESSO INTERNACIONAL DE LEITURA E LITERATURA INFANTIL E JUVENIL, 1., 2008. Anais eletrônicos... Porto Alegre: PUCRS, 2008. Disponível em: $<$ http://www.pucrs.br/edipucrs/CILLIJ/praticas/hora_do_conto__uma_experiencia_maravilhosa_REVISADO_OK.pdf>. Acesso em: 03 out. 2016.

STEFFEN, G. T. As lendas urbanas contemporâneas e o compartilhamento social de recursos autoritativos. [200?]. Disponível em: $<$ http://www.academia.edu/12244132/AS_LENDAS_URBANAS_CONTEMPORÂNEAS_E _O_COMPARTILHAMENTO_SOCIAL_DE_RECURSOS_AUTORITATIVOS $>$. Acesso em: 03 out. 2016.

SYLVESTRE, F. A. O uso de lendas urbanas: uma proposta de leitura. In: ENCONTRO NACIONAL DE LITERATURA INFANTO-JUVENIL E ENSINO, 4., 2011. Anais eletrônicos... Campina Grande: UFCG, 2012. Disponível em: <http://editorarealize.com.br/revistas/enlije/trabalhos/5327a8bbbcbdf8e81f3c446d6013fad9_1 62_17_.pdf>. Acesso em: 03 out. 2016. Não paginado.

TAHAN, M. A arte de ler e contar histórias. Rio de Janeiro: Conquista, 1957.

VENTURA, A. M. A. et al. Projeto lendas urbanas de Londrina: histórias para ouvir e contar. Londrina: Biblioteca Pública Municipal Prof. Pedro Viriato Parigot de Souza, 2012. 